\title{
Management of the Process of Vocational Training of a Competent Specialist
}

\author{
Natalya Rinatovna Balynskaya
}

Oksana Nikolaevna Sinitsina

\author{
Nina Vladimirovna Kuznetsova
}

\section{Svetlana Vladimirovna Koptyakova}

Nosov Magnitogorsk State Technical University, Lenin Ave. 38, Magnitogorsk, Chelyabinsk Region, 455000, Russia

E-mail: svetlana.cop@yandex.ru

\section{Doi:10.5901/mjss.2015.v6n5s4p538}

\section{Abstract}

This article examines the topical issues concerning management of the process of vocational training of a competent specialist. The authors have analyzed this process management technology and the specific features of formation and development of a competent specialist, both when being trained and during the further practical activities. The authors have proven the necessity of establishing a form of the learning process that would combine the individual and collective principles in the best way possible, wherein the opportunities for individual learning would be created under conditions of collective work. The direction for managing the process of vocational training of a competent specialist can be searched for in the combination of team, individual, and collective forms aimed at the formation of production skills in the context of theoretical training. An analysis of the management activity arrangement on specialists training and the structure provided an insight into the inner structure of the management process related to the specialists training within the system of higher vocational education. The constituent elements of the management activity on specialists training are presented, which form a unified functional system featuring the objectives of vocational training as the major factor, which is targeted and followed by all the rest management functions. It is concluded that the actual effectiveness of the suggested system of management of the process of vocational training of a competent specialist can be confirmed by the demand for graduates in the labor market as well as by the appropriate level of their vocational training demonstrated when performing professional activities in the specific production conditions. The article reveals and substantiates the need for managing the process of vocational training of a competent specialist. It examines the concepts of "competence," "competency," and "a competent specialist." Based on the study conducted, the authors propose a system of management of the process of vocational training of a competent specialist from both theoretical and practical points of view.

Keywords: competence, competency, a competent specialist, higher vocational education, management of the vocational training process

\section{Introduction}

The contemporary transformations in the society, the new strategic guidelines in the development of economy, politics, and sociocultural sphere, the fast informatization and agility cause certain changes in the requirements for vocational education. The system of the higher vocational education (HVE) faces the challenge of forming an economically literate, well-rounded, and competent personality of a future specialist ready for modern socioeconomic relations.

In the Addresses of President of the Russian Federation and the Concept of the Long-Term Socioeconomic Development of Russia until 2020, it is rightly pointed out: "the formation of an innovative economy means the transformation of intelligence and the human creativity potential into a leading factor of economic growth and national competitiveness. Herewith, the strategic objective of the state policy in the field of education is to increase the availability of high quality education that will meet the requirements of the innovative development of the economy to the contemporary needs of the society and each citizen" (Order of the Government of the Russian Federation No. 1662-r of November 17, 2008 (revised on August 08, 2009)). Competition of the national education system is a key element of the global competition that requires constant updating of technologies, accelerated mastering of innovations, and fast adaptation to the demands and needs of the rapidly developing world.

A modern university graduate is required to demonstrate an agile and systematic response to the market changes 
and society demands, which imparts the necessity of making new, unconventional decisions and performing continuous innovative activities within the higher education system. Whereas the most important distinguishing features of the promising system of higher education become the fundamentalization of the higher vocational education as an instrument for improving its quality that advances the nature of the entire system of higher education, its focus on the problems of the upcoming post-industrial civilization, and the development of human creative capabilities (Minevrin, 2014).

In Russia, vocational education has been historically developing as a polyfunctional system that reflects complex and contradictory interaction between an individual, the society, the state, and the economy (Belikov, 2009). The modernization of education and its transition to the competency-based paradigm bring the domestic education system into line with the contemporary European requirements, which necessitates the transition from the knowledge-based paradigm in education to the practice-oriented one that is based on the quintet-"knowledge-abilities_skills_practical activity experience-competency" and the implementation of the paradigm shift from "adult education" to "lifelong learning" (Shiryaeva, 2009).

A trend is observed for revising educational objectives and reforming education system at all levels. The overall objective is to apply the innovative strategies and effective methods that allow for agile response to the new economic, social, political, or cultural conditions and meeting the needs for obtaining new knowledge (Boutsiouki, 2010).

Implementation of the new paradigm is intended to assist in overcoming the traditional cognitive orientations of education, actualizing its activity-related component, and leading to the new vision of its contents, methods, and technologies. In essence, this means new realities and challenges arising from the humanization of education and the necessity to prepare specialists for their active and informed participation in the life of the society.

It must be acknowledged that the Strategy 2020, in terms of the "lifelong learning", can only be achieved, wholly or partly, in the event of planning and implementation of the programs and projects along with the national objectives, study of the local and regional factors as well as participation in the developments and innovations through partnership. One of the main principles is to participate in the cooperation between the public institutions, higher education establishments, and other educational institutions in order to promote a greater number of students and improve the learning and selfstudy outcomes (Németh, 2014).

A positive attitude towards learning, recognition of the training activity importance for one's own life, selfconfidence, and satisfaction with the learning process are necessary for successful participation in the educational activity (Boeren et al., 2010).

Management in the context of training qualified, competent personnel within the higher education system should be considered as purposeful, conscious interaction of its members intended to the optimal results achievement.

The general issues concerning the management of the vocational training process were studied by the following scientists: Batyshev, Ivanov, Konarzhevsky, Lazarev, Potashnik, Sergeev, Serikov, Slastenin, Simonenko, Subetto, Shadrikova, et al.

The issue of a competent specialist formation was examined in the works by Verbitsky, Baidenko, Zeer, Selezneva, Zimniaia, Bermus, Tatur, Khutorkovsky, et al. The ideas contained in these works are of undeniable value for solving the problems of a competent specialist training in higher vocational education institutions.

Despite the growing interest of the science and practice to the problems of management of the process of vocational training of a competent specialist, the necessary practical guidelines for its implementation have not yet been developed.

\section{Literature Review}

\subsection{Competency-Building Approach in Vocational Training}

The dynamic socioeconomic and demographic changes shaping the new conditions for the functioning of national education systems assign new tasks to them, which, as a rule, require systemic transformations of structural nature. The Russian system of vocational education is no exception, as it becomes one of the key strategic factors for the development of the Russian economy.

Currently, one of the key problems of the Russian economy, which is the need to improve its competitiveness, is determined by the conflict between the higher vocational education system and the modern requirements to the quality of human capital assets. In accordance with the features of the current state and prospects for the development of economic and social spheres, we can observe an increase in the demand for specialists, change in their role, place, and functions, and enhancement of the requirements for the competency, technological culture, and labor quality.

The traditional vocational training focused on the development of knowledge, abilities, and skills in the subject area 
is increasingly lagging behind the labor market demands. The university graduates are expected to demonstrate the new professional and personal qualities comprising complex thinking, legal and information culture, independent behavior, initiative, creative activity, responsibility for the work performed, agility, and ability to the conscious analysis of personal activities. All these features necessitate the vocational training refocusing on the new vector of development (Kuznetsova, 2013).

The process of lifelong enhancement of the personal, social, and professional qualification allows improving the merits (characteristics) of both separate individuals and groups of individuals. This is a comprehensive and unifying idea, which includes formal and informal learning for acquisition and level enhancement as well as achievement of the highest possible degree of development in different stages and areas of life (Milana, 2012).

Therefore, the main objective of the higher vocational education at the present stage is to prepare a competent specialist who is ready for an independent, effective, and moral solving of the professional and other problems, and who possesses certain general and professional competences. However, the achievement of this objective makes it necessary to improve significantly the quality and efficiency of management of the process of a competent specialist training in the institutions of higher vocational education.

The formation and development of a competent specialist are subject to the impact both at the time of training and during the further practical activity, and require developing adequate technologies for such impact management.

A competent specialist is a self-motivated and diligent employee that efficiently performs his duties and is able to assume responsibility and make decisions in situations pf uncertainty, work effectively in a group towards a common goal, learn independently, making up for the shortage of professional knowledge needed to solve a particular problem.

Competency is an individual characteristic. Competent employees are the main resource of any organization for the acquisition of a competitive advantage. Strategies, business models, products, and services can be copied by the competitors, but the talented and competent employees represent a sustainable source of differentiation (Vathanophas \& Thai-ngam, 2007).

In the Glossary of the VET and Labor Market Terms of the European Training Foundation (ETF, 1997), competence is defined as the ability to do something well or effectively; compliance with the employment requirements; ability to perform specific labor functions. The United Nations Industrial Development Organization (UNIDO, 2002) defines competence as a set of skills, knowledge, and abilities that enable a person to perform a task in a particular type of activity.

Competency is essentially a combination of knowledge, skills, behavior patterns, and attitudes that contribute to personal performance, and a set of knowledge, skills, behavior patterns, and attitudes, by means of which a person must be effective in a wide range of positions and different types of organizations (Bhardwaj, 2013).

According to Zeer, competency assumes that the specialist has not so much significant amount of expert knowledge and experience, as the ability for the knowledge and skills actualization and their well-timed usage during the process of professional functions implementation" (Zeer, 2005).

Competences are interpreted as a unified (harmonized) language for describing academic and professional profiles and levels of higher education. Competence includes not only the cognitive, operational, and technological components, but also the motivational, ethical, social, and behavioral sides-i.e., the learning outcomes, knowledge, skills, and system of value references (Baidenko, 2006).

According to Khutorskoy, competence involves a set of interrelated qualities of a person (knowledge, skills, abilities, and activity methods) specified with respect to a certain range of objects and processes, and necessary for the qualitative and productive activity directed towards them. Competency is a person's possession of a relevant competence consisting of his personal attitude to this competence as well as to the object of his activity (Khutorskoy, 2002).

Competency is a systemic unity that integrates personal, substantive, and instrumental features and components. A categorical base of the competency-building approach is directly related to the idea of goal orientation and targeting of the learning process, wherein competence receives the highest generalized level of the learner's skills and abilities, and the content of education is determined by its four-component model of education content: knowledge, skills, experience in the creative activity, and experience in the valuable relation (Bermus, 2005).

According to the Bologna Agreement, the competency-building approach in generating the content and training programs within the system of vocational education is currently the leading one in the most Western European countries. According to Zimnyaya, the competency-building approach can preserve the cultural, historical, ethnic, and social values if we consider its underlying competencies as complex personality accomplishments that include intellectual, emotional, and moral components (Zimnyaya, 2007). Currently, multiple attempts are made to incorporate the competency-based model into the existing one, and to examine the standards of higher vocational education within the framework of a specialist's competency-based model (Bolotov \& Serikov, 2009). 
From the viewpoint of many scholars, implementation of the competency-building approach would allow, on the one hand, to combine the intellectual and skills-oriented components of education, and, on the other hand, to develop a new ideology for interpreting the content of education being generated "from the outcomes," and to realize the integrative nature of the similar or closely related skills and knowledge that correspond to a relatively wide sphere of culture and activity (informational, legal, etc.).

The competency-building approach in education assumes that learners acquire different kinds of skills that will enable them in the future to act effectively within the situations of professional, personal, and social life. Special emphasis is laid to the skills that allow acting in the new, uncertain, and problematic situations, for which it is impossible to develop appropriate means in advance. Thus, the competency-building approach is the strengthening factor of the applied and practical nature of the entire vocational education (including the subject-focused training).

\subsection{Aspects of the Vocational Training Process Management}

In the context of modernization of the higher vocational education system, the higher education institutions meet both traditional and new challenges of ensuring the employees and learners' adaptation to the ever-changing socioeconomic situation. Solving these problems imposes the new, increased requirements to the management of the vocational training process.

However, the conducted by us generalized analysis of the condition of management of the vocational training process in institutions of higher vocational education allows to ascertain the presence of several typical problems. We agree with Zherdeva that the most important practical problems lie in the fact that the management of the specialists training process in an institution of higher vocational education features the following problems:

1) Poor proactive response to the changing situation in the socioeconomic and sociocultural environment;

2) Absence of the management process adaptation to the needs of the institution's learning process and demands of the business community;

3) The targeted nature of the learning process managements and of its focus on achieving the desired results is not provided;

4) The values and objectives of an institution of higher vocational education are not coordinated with values and objectives of employees as they should in a social institution;

5) Employees are not motivated for innovations in the learning process (Zherdev, 2006).

It should be noted that the changes occurring within the socioeconomic development of the society require specific organizational actions and certain management decisions. Simonov highlights that "the learning process is an integral dynamic system. Its management also requires a systematic approach. Therefore, it is necessary to provide a deep theoretical analysis of the essence of the learning process as a system, the regularities of its functioning and development as well as the nature and patterns of the pedagogical management as a whole" (Simonov, 2007).

It is the transition to a post-industrial economy that is inherent in the problem of competent specialists training. Today, the issue of developing a system of management of the specialists training process is pushed to the foreground, which includes the following:

1) Research, methodological, and information support of educational institutions;

2) Support and development of innovative activity in education and innovative educational institutions;

3) Implementation of training, retraining, and advanced training of academic teaching personnel, involvement of public and business community in the process of solving education development problems.

All the constituent elements of the management activity of specialists training form a unified functional system, wherein the backbone factor is the training and education objectives, which are focused on and subject to all other management functions. In turn, management of the vocational training process is understood as the purposeful interaction of a teacher and students through the scientifically grounded planning, implementation, motivation, and control of their activities ensuring the formation of future specialists of optimum quality and the full use of their knowledge, skills, and competences.

Managing the process of a competent specialist training is obviously possible in the presence of creativity, creative activities, possibility of problem tasks solving, self-awareness as well as the ways of transformative activity with a specific outcome acquisition. In the conditions of reflective learning, there is a shift of educational emphasis towards the integration of the cognitive and personal experience, i.e. a task to perform a reverse operation occurs, which is to introduce the personality context into the cognitive issue and to bring the students in a reflexive position with respect to the training materials, fellow students, and themselves. Reflection provides not only the objectified view of the situation and the reasons for the difficulties, but also the foundation for the activity intended to correct the situation. 
The way the management process is arranged and triggered on the level of an educational institution as a whole and on the level of "teacher-student" exercises significant influence on the quality of a graduate training. For this very reason, the task of optimizing the management of the process of a competent specialist vocational training is one of the general challenges in the conditions of a vocational school.

In the process of vocational training of a competent specialist, the following stages of the teacher's management activity can be clearly visible:

1) Analysis of the original situation, determination and setting of the learning objective, and its comprehension by the students;

2) Work planning and selection of the content and means for the objective achievement-presentation of a new fragment of the learning material in different ways and conscious perception;

3) Performance of the training operations by learners, organization of the training activity of teachers and learners (organization and self-organization of learners during the implementation of new learning material to its optimum level under the conditions given);

4) Feedback arrangement, management and correction of the work on mastering the material content, and selfcontrol;

5) Analysis and self-awareness, assessment of the learning outcomes;

6) Preparation and work of learners outside an educational institution.

The model of higher vocational school is based on the seven elements: objective-tasks-principles-contentforms-methods-outcomes. The decisive element is the projected outcomes, i.e. a competent specialist demanded by employers and the society as a whole.

Teacher's activity is aimed to identify the conditions of the training activity organization, the observance of which will allow a learner to be consciously familiar with the subject, to update the acquired knowledge and skills, to exercise self-control, and build competences. Each management act must introduce some changes both in the nature of the learner's activity, and in the process of his formation as a personality. For this purpose, a teacher should analyze the objectives of vocational training as applied to the various learning situations, to a specific academic subject, and to each its section.

In developing the strategy for managing the process of vocational training of a competent specialist, a teacher must assess what knowledge, for what purpose, and to what extent he is going to form in a learner as a result of his study of specific learning material. To do so, the peculiarities of certain types of students' activities must be taken into account that will provide for the achievement of the objectives set. A certain sequence of the students' actions, operational structure of these actions (performing, estimating, and orientating), and finding the ways to motivate participation in the cognitive activities are of significant importance. This is the first management task within the teaching process. The second problem is reduced to the implementation of the principle of activity and self-management in the cognitive activity of students and consists in the arrangement of training sessions, wherein the teacher would guide and intensify the process of active, independent, and productive work of each student.

The practice of the learning process conduction shows that in the conditions of the traditional training group existence, it is difficult to execute a differentiated approach in training and education, as well as fully reveal and apply the individual characteristics of each student directing them to the development of general and fast pace of teamwork.

A necessity arises to establish such a training form that would combine the individual and collective principles in the best way possible, wherein the opportunities for individual learning would be created under conditions of collective work. It seems reasonable to create such micro groups within the existing learning groups that would in an orderly and inclusively manner reflect the specificity of the special subject being studied. This allows arranging such a learner-group interaction based on the principles of independence and activity, which will be fully consistent with the objectives of the management of the process of vocational training of a competent specialist.

This will enable the personal experience concentration, qualitative change and intensification of the collective and group relations by improving the cognitive activity experience in relation to the specifics of training in a vocational school.

\section{Methodology}

\subsection{Training in Small Groups}

The educational standard suggests groups of 25 persons within the system of the higher vocational training. This quantity prevents a teacher from conducting an individual training of each student. For some subjects according to the curriculum, it is permitted to divide groups into subgroups of 12-15 persons. This facilitates the teacher's work, but does not 
completely solve the problem of individualization, therefore teachers continue their search.

Within the process of the student's individual independent work, at the maximum manifestation of his initiative, efficiency, and individual interests, he acquires competences, knowledge, abilities, and skills and enhances selfassessment.

Training of students in small groups (4-6 people) is effective, as each student has the opportunity to master the learning material on different levels, in his own pace, and depending on his personal abilities and individual personality traits. The form of class work in small groups attracts students, as all of them are active self-management participants. This form allows them to accomplish their pursuance of joint search for the solution of the task set, and activates their emotional, mental, and contact attitude.

When training in groups (of more than 20 people), the individualization progress descends to the lowest point of its development, as this system is focused on the average pace of academic advancement without taking into account individual characteristics of students. Therefore, such quantity does not allow the teacher to perform individual training of each student. The most essential drawbacks of this type of training include its better focusing on the memory and not on the thinking. This training also contributes little to the development of creative abilities, independence, and proactive attitude. The learning and teaching process is of increasingly reproductive nature. Moreover, there is no possibility of adapting the pace of learning to the different individual psychological characteristics of students (contradiction between the frontal training and the individual nature of knowledge assimilation).

In the conditions of learning within micro groups, the managerial and organizing activity of a teacher becomes particularly important, the nature and constituents of which are distinguished by the particular orientation and variability at each training stage.

\subsection{Stages of Training in Small Groups}

Due to different levels of activity and independence of learners in the process of vocational training of a competent specialist, the following stages characterized by specific features can be distinguished.

The first stage. Student's introduction into the specificity of the subject studied.

The main characteristic of this stage is that it is focused on the formation in learners of the necessary methods for studying a special subject, manifesting a primary activity and accompanying independence. The content of the teacher's activity at this stage is determined by the strict and precise planning and dosing of the learning material, arrangement and management of the nature, methods, and content of the learner's activity.

The second stage. Establishment and arrangement of the communication functioning within a training group. The main characteristic of this stage is that it is focused on the arrangement of micro groups, their activities, and selection of the most appropriate working methods of individual learners, a micro group, and the entire training group.

The content of training material is significantly differentiated and complicated, the methods of training become more diverse, but at the same time, they have more pronounced specificity and reliance on independent behavior. The monitoring function approaches the activity management function.

The third stage. Organization of the micro groups' interaction with the external environment. The third stage of the teacher's activity is distinguished by the necessity to focus the process of vocational training on the employer's needs. The implementation of training is carried out based on the relations established inside and between the micro groups, and the necessity of their strengthening during the period of the course and diploma work development.

Advantages of the micro groups' establishment within the process of vocational training of a competent specialist:

1) Establishment of effective communications and their transformation into the energy of action focused on acquiring knowledge, practical skills, and competences.

2) Ultimate intensification of the learners' training activity and its clear and efficient management. In this case, the teacher has to deal with a clearly organized, closely related, and, therefore, better manageable group of people, which is kind of an enlarged unit, out of which the academic group is formed.

3) The possibility for a teacher to influence on the student's inner circle, and thus on each individual included therein.

4) The possibility to build effectively cognitive and practical skills and competences creating the framework for the vocational training implementation on a higher level.

5) The possibility to compare the teamwork results of small groups.

6) The timely and prompt correction of the activity performed by one micro group in relation to another one.

7) Implementation and stimulation of the learners' interest to the subject during the process of vocational training.

8) The possibility to develop creative abilities of the learners. 
The current understanding of the education quality is confined not to the student proficiency, but to the process of becoming a competent specialist, i.e. it assumes that a graduate is ready to succeed in life in the conditions of the modern world uncertainty, and includes not only the substantive, but also the social and personality components.

It is recommended to perform the teacher's work on establishing micro groups as follows:

1) To examine the level of knowledge of the group's learners, and the degree of their proactive attitude (academic and public).

2) To determine formal and actual leaders.

3) To introduce all the advantages of this training system to the group, which is expected to be divided into micro groups, by means of meetings with senior students, demonstration of their lecture notes, etc., and also demonstrate them the structure of micro groups and requirements to its members and the leader.

4) To divide the training group into micro groups.

Herewith, it should be taken into account that the optimum number of a micro group's members is 4-6 persons. The formation of the micro groups must satisfy the following conditions:

1. Compliance with a certain ratio among the number of successful, average and weak learners combined into one micro group;

2. Acceptance by the core members and the group as a whole of the micro group's nominal membership (all micro groups must be equal according to their academic progress);

3. Approval of the special subject teacher.

5) To choose the micro group's leader.

Each micro group must be headed by a senior student out of the group's studying members who, during the process of training, will be the organizer of all works, at which the micro group is independently solving individual problems of both theoretical and practical nature. When choosing the micro group's foreman, the teacher needs to familiarize his learners with those personal and professional qualities that must be possessed by the micro group's foreman: good knowledge, desire to assist in learning, organizing skills, authority in the group, and modesty.

At the initial stage of the micro group development, which is characterized by the "formal" publicity of its members and absence of the common goal acknowledged by the learners, the teacher should assume the major role in the organizational and management activity of the training micro group: he provides effective assistance in its work, plans training and productive activities, and keeps records of the outcomes of the micro group members' work. Subsequently, the teacher must change the role of a subject expert, leader for the role of a coordinator, partner, representative of the scientific sphere, expert, researcher, etc., depending on the forms and methods of classes.

The actual effectiveness of the suggested system of management of the process of vocational training of a competent specialist can be confirmed by the demand for graduates in the labor market as well as by the appropriate level of their vocational training demonstrated when performing professional activities in the specific production conditions.

It should be taken into account that each of the considered structural elements of control over the pedagogical process with all its characteristics can hardly exists in a separate pure form. Of course, all of them are tightly bound to each other with the interpenetrating elements. However, according to their leading role and nature, they can be conventionally determined within the proposed by us ratio, and recommended for application when managing the process of vocational training of a competent specialist.

\section{Conclusion}

The paper considers management of the process of vocational training of a competent specialist as an integral process. It describes the approaches to the management that allow considering it as a social and pedagogical issue. An analysis of the management activity organization in compliance with the stages (planning-arrangement-motivation-control) and the structure (objective-tasks-content-forms-methods-outcomes) allowed to penetrate into the internal structure of the management of the specialists training process within the system of the higher vocational education. The concepts of "competence", "competency", and a "competent specialist" were studied.

As the analysis conducted has shown, the content of the vocational training, method of its establishment, form of functioning in the real learning process in that form, in which it currently exists, does not fully correspond to the main purpose of the educational process, i.e. to the training of a competent specialist that meets all the requirements of a contemporary employer, as the first structural element prevails in the form of knowledge and skills.

Thus, the answer to the questions "what to teach?" and "how to teach?" should not only provide for the assimilation of the experience as such, but also ensure creative development and formation of the personal references and priorities. 
This problem is suggested to be solved by improving the learning process through the following actions:

1) Combination of the group, individual, and collective forms aimed at the production skills formation in the conditions of theoretical training.

2) Problematic construction of the training material's content.

3) Activity approach within the learning process arrangement.

The effectiveness of the suggested system of management of the process of vocational training of a competent specialist can be confirmed by the demand for graduates in the labor market as well as by the appropriate level of their vocational training demonstrated when performing professional activities in the specific production conditions.

Management of the process of vocational training of a competent specialist through the combination of different forms of training, problematic construction of the training material's content, and implementation of the activity approach in the learning process organization is found to be effective.

\section{References}

Baidenko, V. I. (2006). Specifying the composition of the graduates' competences as the necessary stage of designing the state educational standard of higher vocational education of the new generation: guidance manual (p. 72). Moscow: Research center concerning the problems of the quality of specialists training.

Belikov, V. A. (2009). Vocational education. Methodology of activity: Monograph (p. 334). Moscow: Humanitarian Publishing Center VLADOS.

Bermus, A. G. (2005). Problems and Perspectives for the Implementation of a Competency-building Approach in Education. Internet Journal "Eidos". Retrieved from http://www.eidos.ru/journal/2005/0910-12.htm

Bhardwaj, A., \& Punia, B. K. (2013). Managerial competencies and their influence on managerial performance: A literature review. International Journal of Advanced Research in Management and Social Sciences, 2, 5. Retrieved April 04, 2015, from: https://www.academia.edu/5450517/

Boeren, E., Nicaise, I., \& Baert, H. (2010). Theoretical models of participation in adult education: The need for an integrated model. International Journal of Lifelong Education, 29(1), 45-61.

Bolotov, V. A., \& Serikov, V. V. (2009). Competency-based model: From the idea to the training program. Pedagogics, 10-11.

Boutsiouki, S. (2010). Dynamics and potentiality of postgraduate students regarding lifelong learning: A Greek case. International Education Studies February, 3(1).

Glossary of the Labor Market Terms, Development of the Standards of Training Programs and Curricula. (1997). European Training Foundation (ETF).

Khutorskoy, A. V. (2002). Key competences and educational standards. Internet Journal "Eidos". Retrieved from http://www.eidos.ru/ journal/2002/0423.htm

Kuznetsova, N. V. (2013). Competency-building Approach to the Vocational Training of the Managerial Human Resources: Employers' Requirements. Innovation Bulletin Region, 4, 64-68.

Milana, M. (2012). Political globalization and the shift from adult education to lifelong learning. European Journal for Research on the Education and Learning of Adults, 3(2), 103-117.

Minervin, I. G. (2014). Practice-oriented model of the modern specialist training: Monograph (p. 152). Yuzhno-Sakhalinsk: Sakhalin State University Publishing House.

Németh, B. (2014). Lifelong learning, higher education and the development of learning communities (p.119). Published by University of Pécs Faculty of Adult Education and Human Resources Development. Printed by Virágmandula Ltd. Pécs.

Order of the Government of the Russian Federation No. 1662-r "On the Concept of the Long-Term Socio-Economic Development of the Russian Federation until 2020" of November 17, 2008 (revised on August 08, 2009). Retrieved Sepetember 14, 2014, from http://www.consultant.ru/document/cons_doc_LAW_90601/?frame=1

Shyriaeva, V. A. (2009). Formation of the universal key competence by means of TIPS: Training toolkit (p. 88). Saratov: Nauka Publishing Center.

Simonov, V. P. (2007). Pedagogical management (p. 264). Moscow: Vysshaya Shkola.

United Nations Industrial Development Organization. (2002). UNIDO Competencies. Retrieved from: http://www.unido.org

Vathanophas, V., \& Thai-ngam, J. (2007). Competency Requirements for Effective Job Performance in the Thai Public Sector. Contemporary Management Research, 3(1), 45-70.

Zeer, E. F., Pavlova, A. M., \& Symaniuk, E. E. (2005). Modernization of vocational training: Competency-building approach: Workbook (p. 216). Moscow: Moscow Psychological and Social Institute.

Zherdev, A. V. (2006). Implementation of the Project Method for Managing the Training Process in the Educational Institutions of the Secondary Vocational Education (for Training Motor Vehicle Driver). Moscow.

Zimniaia, I. A. (2007). Key competences as the effectively targeted basis of the competency-building approach in education: author's version (p. 40). Moscow: Research center concerning the problems of the quality of specialists training. 